\section{Translational and Reverse Translational Research Supporting Precision Medicine: Acanthamoeba Keratitis as a Model of Linkage between Clinical and Basic Research Focused on Personalized Ophthalmology}

\section{Fábio Ramos de Souza Carvalho*, Linda Christian Carrijo-Carvalho and Denise de Freitas}

Department of Ophthalmology and Visual Sciences, Paulista School of Medicine, Federal University of São Paulo, São Paulo, BrazilManipal University, Manipal, Karnataka, India

\begin{abstract}
Translational Research is defined as Scientific Research conducted in order to apply discoveries from basic sciences for developing new applications to improve clinical practice and patient's welfare, including rapid, specific and sensitive diagnostic methods, and safely effective therapeutic agents. The translational approach "from bench to bedside" has limited success if there is not a reverse path. Reverse translational research ensures the feedback "from bedside to bench" and helps identifying specific subjects that demand laboratory investigation or establishing inferences between laboratory findings and clinical observations. Precision medicine employs scientific advances and discoveries from basic sciences on the clinical research to provide an accurate diagnosis followed by a personalized care for each patient, selecting the most suitable therapy pattern for a specific etiology. In the genomic era, a full and integrative cycle between these three areas of translation is now possible. Management of knowledge concerning the application of molecular biology, biochemistry and cellular technologies can offer personalized application of basic sciences' tools within a specific sub-specialty of ophthalmology. Advanced basic science supported by current omics technologies provides a potential linkage between the standardized experimental data-from in vitro and in vivo assays under controlled laboratorial environment and the applied science

*Corresponding author: Fábio Ramos de Souza Carvalho, Department of Ophthalmology and Visual Sciences, Paulista School of Medicine, Federa University of São Paulo, São Paulo, SP, Brazil, Tel: +551155764838; Fax: +551150852004; E-mail: frscarvalho@unifesp.br

Citation: Carvalho FRS, Carvalho LCC, Freitas DD (2014) Translational and Reverse Translational Research Supporting Precision Medicine: Acanthamoeba Keratitis as a Model of Linkage between Clinical and Basic Research Focused on Personalized Ophthalmology. J Ophthalmic Clin Res 1: 001
\end{abstract}

Received: May 24, 2014; Accepted: July 29, 2014; Published: August 12, 2014 used in clinical routine. The linkage between both basic and applied sciences focuses on the improvement of human health. The three main aspects of cyclic interaction constituted by the two-way approaches between bench top and bedside with main focus on the application of precision medicine to provide knowledge about human diseases are illustrated here with examples in the context of Acanthamoeba keratitis. This paper presents translational approaches in the ophthalmology field and visual sciences, available technologies, and promising issues to be investigated through reverse translational research, such as searching for specific biomarkers, setting up prognostic factors and recognizing differential profiles of host resistance and pathogen virulence. These advances may render benefits for the practice of personalized medicine.

Keywords: Translational science; Diagnostic precision; Reverse translational research; Personalized medicine; Acanthamoeba keratitis; Prognostic factors; Biomarkers; Genome; Omics

\section{Introduction}

A patient comes to the eye care service, complaining of blurred vision, eye pain, and sensitivity to light, redness, and tearing. After ocular examination, the ophthalmologist observes that the cornea is affected, with an anterior stromal ring infiltrate and uveit is as marked signs. Samples are sent for laboratory diagnosis, under suspicion of infectious keratitis. Microbiological culture of corneal scrapings is positive for Acanthamoeba the patient wears soft contact lens with confirmed Acanthamoeba Keratitis (AK). Despite treatment with poly hexamethylenebiguanide, in combination with hexamidine, and topical steroid for several months, the patient has recurrent corneal and scleral inflammation episodes and the disease extends for over two years, with recurrent positive cultures, surgical intervention by deep lamellar keratoplasty and the nenucleation [1]. This is one acute and sight-threatening microbial in fection of the cornea, which could be associated with history of pain, photophobia, visual impairment followed by recurrent corneal infection, in flammation and poor outcome. The specialized literature presents several otherocular diseases and pathologies provided by clinical observation in the routine of sub-specialty fields of ophthalmology, describing the development of complications to afford correction of visual acuity and poor therapeutic responses [1-4].

The present picture raises the question of which factor determines the disease severity: the host response or the pathogen virulence. Advanced knowledge on this issue could have saved the patient's eye. The association of the scientific tools and confident findings provided by the research bench, the careful observation and specialized analyses from the clinical practice associated with the application of scientific and practical discoveries to improve patients' health care can potentially benefit the management of $\mathrm{AK}$, and many other ocular diseases. In an ideal scenario, specific profiles of both patient and Acanthamoeba could be recognized, based on previously characterized patterns and prognostic models. The knowledge and technologies translated from research into Precision Medicine (PM) guide the selection of appropriate treatment, based on the patient's predicted response and the pathogen virulence/resistance profile. 
Translational Research (TR) aims to apply the knowledge and technologies from basic sciences in the development of studies focused on a medical issue. At the bench, laboratory findings should present a direct means to improve prevention, diagnosis and treatment. Reverse Translational Research (RTR) takes into consideration clinical findings or clinical aspects of a disease observed at the bedside, to direct the design of laboratory assays using appropriate in vitro and in vivo models in the context of TR. Figure 1 represents the association of translational investigations and PM.

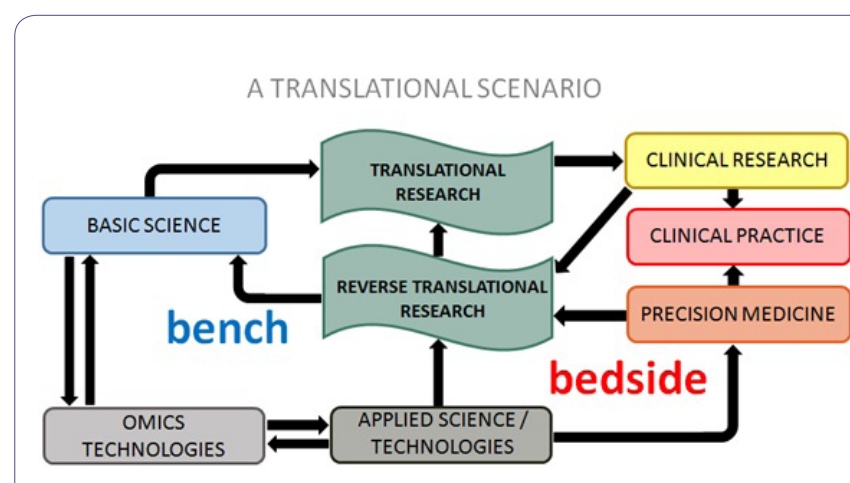

Figure 1: The cyclic interaction of translational research, reverse translational research and precision medicine: The black arrows represent the flow of information between laboratory (bench) and clinical findings (bedside). The development of omics technologies, supported by basic and applied sciences, influence translational research and precision medicine.

The following topics describe how the association of TR, RTR and PM is possible, and the current translational findings, taking $\mathrm{AK}$ as an example. This article also seeks to open a broad discussion on the contribution of TR and its aspects to the improvement of clinical care and PM. Thus, we present perspectives concerning the current scientific trends which have been applied complementarily to the available technologies for translational studies, with potential diagnostic and therapeutic applications in the field of ophthalmology and visual sciences.

\section{Translational Research}

Translational Research can help understand how virulence factors expressed by a pathogen relate to the patho physiology of disease. Furthermore, the enhancement of the bench top research through the application of standardized basic and molecular sciences could be able to improve laboratory diagnoses procedures and to evaluate early therapeutic interventions. It is believed that an early start of a specific therapeutic procedure may increase the chances of restoring normal health conditions with minimal side effects and maximum patient's quality of life at the bedside [4,5]. For instance, laboratory assays of Acanthamoeba strains and clinical isolates on in vitro drug sensitivity tests [1,6,7] development of new therapeutic patterns [8,9] the characterization of differential virulence factors, as well as investigation of the cytopathic effects in cell culture and animal models [10-12] provide meaningful data.

Application of currently available Molecular Biology approaches represents a refinement in the laboratory diagnosis. Identification of Acanthamoeba genotypes through DNA amplification by PCR or real-time PCRoffers rapid results, specificity and sensitivity [13-16]. Real-time PCRcan also give an estimate of parasite load through quantification of DNA copy number, which is associated with poor outcome [17]. Other possible applications of molecular techniques are detection of new species and genotypes of a specific microorganism
$[18,19]$ epidemiological survey, establishment of etiological link between source and infection [14,20] recognition of physiological differences (eg growth rate, metabolism) and screening of virulence profiles observed on in traspecific variations of pathogens [21,7]. However, the use of molecular diagnostics alone has not delivered the expected impact in clinical practice and patients' health. In the same way in vitro and in vivo laboratory findings have not been easily translated into clinical application-hence the role of RTR.

\section{Reverse Translational Research}

Reverse translational research can clarify how host response affects disease prognosis. From a series of clinical reports, identification of the signs and symptoms associated with a poor prognosis [22-24] is a starting point. In addition, analysis of differential therapeutic responses among individual case descriptions, retrospective or prospective epidemiological surveys and clinical trials can contribute to direct the management of disease and decide about the treatments with the greatest chance of success in different situations [2,25-27]. In corneal diseases by microbial infection, such as AK-for which there is no consensus therapythese studies, are particularly important. The association of clinical observations with laboratory findings is a step forward that can lead to significant advances in clinical practice. For example, the association of disease severity with Acanthamoeba genotype [15] or with the differential expression of amoebic proteases [12]. Sometimes laboratory findings do not correlate with clinical observation, drawingattentionforinvestigation ofdifferentaspectsofthehost-parasite interaction. The lack of correlation between the in vivo resistance observed in AK subjects with persistently positive cultures after treatment with diamidines and/or biguanides and in vitro drug sensitivity provide a direction for the study of poor therapeutic response [1]. At present the role of host immune and inflammatory responses in $\mathrm{AK}$ is not understood. Knowledge of the panel of key markers of immune and inflammatory responses in AK patients could help to understand the differences in therapeutic responses and clinical outcomes, and also to identify prognostic markers and therapeutic targets. Lower levels of anti-Acanthamoeba IgA antibodies in tears and serum were observed in AK patients in comparison to healthy subjects, indicating an immune-related susceptibility $[28,29]$. Genetic factors can affect the patient's response to pathogen invasion and represent another issue for translational studies. For example, the activation of inflammatory cascade mediated mainly by toll-like receptor 4 (TRL4) and triggered by virulent strain of Acanthamoeba was recently demonstrated by in vitro and in vivo experimental assays [30]. Single nucleotide polymorphisms of the gene encoding TRL4 have been correlated with susceptibility to infectious and inflammatory diseases in human subjects [31]. Investigation of the genomic profiles among AK patients, by using RTR, could demonstrate the association of TLR4 genetic polymorphisms with increased susceptibility to disease. Further laboratory assays concerning the recognition and polymorphisms of receptors expressed by the cornea tissue in the contact with metabolic products of the protozoa could confirm TLR4 as a potential therapeutic target and a promising prognostic marker in the management of AK.

The omics field in ophthalmology and visual sciences is currently in increasing progress. The advance of genetic therapy focused mainly on earlier detection and treatment of complex pathologies from congenital or acquired primary human source has been motivating an increasing number of ophthalmologists to develop critical analyses about the functional role of basic science applied to the improvement 
of patients' health at the bedside. Analyses of genomic, transcript omic, proteomic, and metabolomic technologies have demonstrated an integrative function in the investigation and treatment of pathophysiological processes with a higher degree of complexity, related to eye diseases at levels of DNA, RNA, protein and cell/tissue, respectively [32-38]. Furthermore, the use of protein and antibody arrays [39] and the next-generation DNA sequencing technology $[40,41]$ supports the earlier detection by screening of proteomic, transcript omic and genomic profiles, respectively, in eye diseases and ocular syndromes which are well-defined in clinical practice, but not fully-investigated for gene therapy approaches and treatment outcome. As examples, we have ligneous conjunctivitis, glaucoma, strabismus and retinitis pigmentosa. In this context, the increasing availability of personal genome and validation of biomarkers are promising tools for PM and personalized therapy [42].

\section{Towards Precision Medicine}

Molecular Genomics have revolutionized the field of medical, biological and biomedical sciences. The access to genomic information of a specific etiological agent by molecular diagnosis techniques has demonstrated to be sensible, specific and time-safe. Consequently, the establishment of an early and effective treatment could be implemented. Mirnezami and collaborators elegantly described in the literature the theoretical and functional roles of $\mathrm{PM}$, which require the participation of patients and medical community, not only as subject of investigations of pathologies and therapeutic patterns, but also as fundamental factors to improve health services to the community. It will also provide the patient with the most appropriate treatment regimen from dosage and treatment time specified in advance, with minimal side effects and maximum efficacy [43]. For example, in the external diseases of the ocular surface and cornea PM considers the available data on pathogen virulence predicting host immune responses and evaluating prognostic models into the patient's context. In the PM scenario the selection of an appropriate therapy is an essential aspect for the quality of patients' health, and all relevant information should be considered in the clinical follow- up, such as the individual genetic profile, associated risk factors, choice and expression of potential biomarkers, specific signs and main side symptoms.

Once $\mathrm{AK}$ is a sight-threatening disease, characterized by complex diagnosis and therapy, which requires long-term treatment and long-term follow up, Personalized Medicine, supported by precision diagnosis, is important in the management of the disease. Despite the majority of patients being contact lens wearers $[4,44]$ as the case mentioned at the beginning, some AK cases are not associated with environmental risk factors [3]. Patients usually have a previous clinical diagnosis of bacterial fungal or herpes simplex virus keratitis before a laboratorial diagnosis for AK $[3,4,45]$. AK may present similar clinical features to herpetic keratitis, contributing to diagnostic delay and late delivery of appropriate medical therapy $[4,45,46]$. According to the current data early treatment is associated with a better prognosis $[4,5]$.

Prolonged treatment requires discipline of patients with amoebic keratitis in constant application of antimicrobial agents in the first months post-diagnosis and continuous monitoring from the ophthalmologist in order to minimize the cytotoxic effects of chemical drops and avoid possible clinical complications such as iris atrophy, cataracts and glaucoma [4]. In this context, for example, PM could enhance the diagnosis and therapy of AK: early detection of protozoa by conventional culturing method of viable cysts from corneal scrapings, under optimized incubation conditions, associated with estimation of viable parasite load by DNA copy number by molecular techniques have the potential to monitor the length of treatment, dosage adjustments, requirement of combined therapy, and the use of topical steroids. Optimal therapeutic prescription reduces the corneal exposure to the potential toxicity of biocides used for $\mathrm{AK}$ treatment [47-49]. Treatmentwithvoriconazolehasbeenproposedfor AK unresponsive to conventional therapies with biguanides and/or diamidines [50,51]. Prescription of this triazole derivative chemical requires careful attention to dosage regimen due to drug interactions, genetic variations in drug metabolism and potential hepatic toxicity [52]. Furthermore, Lorenzo-Morales et al. elegantly described in a review article published recently the application of azole compounds other than voriconazolehave been proposed for $\mathrm{AK}$ unresponsive to conventional therapies to reduce the infective process in severe cases of the disease for example, the association of miconazole and propamidine or oral it raconazole associated with the topical use of miconazole and ketoconazole [53]. For this reason, serum levels of hepatic enzymes are currently used as standard biomarkers for therapeutic monitoring, mainly of fungal infections. Pharmaco genomic models based on genetic polymorphisms of drug-metabolizing enzymes and drug transporters have the potential to improve medical decisions based on individual genomic profiles [54].

(Figure 2) presents an outlook of possible benefits of the cyclic interaction of TR, RTR and PM in the context of AK. The proposed scheme can give a general idea of how the flow of information between bench and bedside could benefit an individual case. Table 1 summarizes some examples of potential benefits of translational findings to precision ophthalmology in the management of AK. Discoveries about the pathophysiology of disease, diagnostic and therapy tools currently available and those which should be proven effectual in the near future especially with the increase of omics data are presented in Table 1. As Scientific Investigation is a dynamic and interactive process an ambiguity may exist between the translational findings with current and future applications. The given examples represent a part of the many possibilities to be explored through the association between the three aspects in the study of AK.

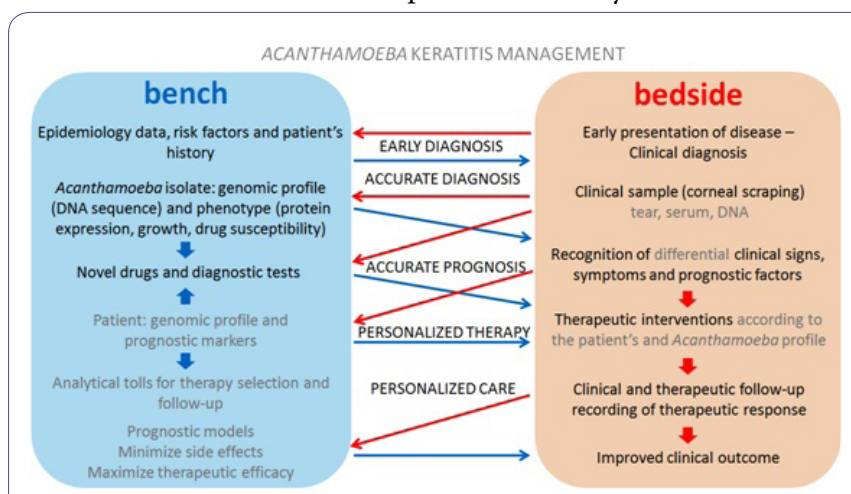

Figure 2: Association between translational studies and precision medicine in benefit of Acanthamoeba keratitis management: Blue arrows represent the flow of information from bench to bedside (translational research). Red arrows represent the flow of information from bedside to bench (reverse translational research). Potential applications from translational discoveries are indicated in gray letters.

In conclusion $\mathrm{AK}$ is a complicated disease that may be substantially benefit from basic and clinical research. Efforts of TRare necessary for early and accurate diagnosis and the development of new therapies to overcome pathogen resistance and to reduce drug toxicity to the host 
Citation: Carvalho FRS, Carvalho LCC, Freitas DD (2014) Translational and Reverse Translational Research Supporting Precision Medicine: Acanthamoeba Keratitis as a Model of Linkage between Clinical and Basic Research Focused on Personalized Ophthalmology. J Ophthalmic Clin Res 1: 001.

\begin{tabular}{|c|c|c|}
\hline Characteristics & Current knowledge & Future perspectives \\
\hline \multirow{4}{*}{ Acanthamoeba } & $\begin{array}{l}\text { Culture from corneal scraping, } \\
\text { followed by amplification and } \\
\text { sequencing of } 18 S \text { ribosomal } \\
\text { DNA for accurate diagnosis [13] }\end{array}$ & $\begin{array}{l}\text { Early diagnosis based on } \\
\text { culture independent DNA } \\
\text { amplification. Estimate } \\
\text { of Acanthamoeba load by } \\
\text { real-time PCR [17], providing } \\
\text { data for personalized therapy }\end{array}$ \\
\hline & $\begin{array}{l}\text { Acanthamoeba phenotype } \\
\text { associated with pathogenic } \\
\text { strains: cytopathic effect, higher } \\
\text { growth rate and temperature } \\
\text { tolerance }[21,55,56]\end{array}$ & $\begin{array}{l}\text { Worse disease prognosis } \\
\text { associated with non-T4 geno- } \\
\text { type }[7,15] \text { and genetic profile } \\
\text { (eg phylogenetic clustering } \\
\text { [21] and genes coding for } \\
\text { differential virulence factors) }\end{array}$ \\
\hline & $\begin{array}{l}\text { The mannose induced protein } \\
\text { (MIP-133) associated with } \\
\text { pathogenesis of AK, inducing } \\
\text { epithelial cell death and } \\
\text { collagen degradation in the } \\
\text { cornea [10] }\end{array}$ & $\begin{array}{l}\text { MIP-133 as a therapeutic } \\
\text { target [10] or biomarker. } \\
\text { Differential expression of } \\
\text { serine proteases associated } \\
\text { with disease severity [11,12] } \\
\text { directing a personalized } \\
\text { therapy }\end{array}$ \\
\hline & $\begin{array}{l}\text { Cyst resistance to diamidines } \\
{[1,4] \text { variable drug susceptibil- }} \\
\text { ity of different Acanthamoeba } \\
\text { strains, species or genotypes } \\
{[6,15,48]}\end{array}$ & $\begin{array}{l}\text { Validation of an in vitro test } \\
\text { for identification of resistant } \\
\text { strains that correlates with } \\
\text { clinical response. New } \\
\text { therapeutic agents eg statins } \\
\text { [57] miltefosine [58] and gene } \\
\text { silencing approaches eg } \\
\text { siRNA targeting Acanthamoe- } \\
\text { ba myosin [9] and ergosterol } \\
\text { biosynthesis [57] }\end{array}$ \\
\hline \multirow{5}{*}{ AK patient } & $\begin{array}{l}\text { Risk associated with contact } \\
\text { lens wear }[25,44] \text { and with low } \\
\text { tear levels of anti-Acanthamoe- } \\
\text { ba IgA antibody [28] }\end{array}$ & $\begin{array}{l}\text { Improvement of a preventive } \\
\text { care for patients with } \\
\text { increased risk factors. De- } \\
\text { velopment of antibody-based } \\
\text { diagnostic test }[28,29] \text { and } \\
\text { therapeutic approaches }\end{array}$ \\
\hline & $\begin{array}{l}\text { Radial keratoneuritis and ring } \\
\text { infiltrates as characteristic signs } \\
{[4,22,24]}\end{array}$ & $\begin{array}{l}\text { Recognition of signs and } \\
\text { symptoms for accurate diag- } \\
\text { nosis. Recognition of signs } \\
\text { and symptoms indicative of } \\
\text { best/worst prognosis }[23,24]\end{array}$ \\
\hline & $\begin{array}{l}\text { Monotherapy with a biguanide } \\
\text { or combined therapy using } \\
\text { biguanides and diamidines with } \\
\text { adjustable therapeutic regimen } \\
\text { is effective in several cases, } \\
\text { leading to a best outcome } \\
{[4,25,27] \text {. Ocular toxicity of cur- }} \\
\text { rent anti-Acanthamoeba drugs } \\
{[4,47,48,49]}\end{array}$ & $\begin{array}{l}\text { Proof of efficacy of off-label } \\
\text { drugs [50,51] or novel an- } \\
\text { ti-Acanthamoeba compounds } \\
\text { previously approved in } \\
\text { pre-clinical trials. Identifi- } \\
\text { cation of the patient's drug } \\
\text { metabolizing profile through } \\
\text { pharmacogenomics tests [54] } \\
\text { to implement personalized } \\
\text { therapy }\end{array}$ \\
\hline & $\begin{array}{l}\text { Inflammatory response is medi- } \\
\text { ated by TLR4 receptor [30] }\end{array}$ & $\begin{array}{l}\text { TLR4 as a therapeutic target. } \\
\text { Identification of TLR4 poly- } \\
\text { morphisms [31] associated } \\
\text { with differential prognosis and } \\
\text { establishment of personalized } \\
\text { therapy }\end{array}$ \\
\hline & $\begin{array}{l}\text { Available omics technologies, } \\
\text { complex analysis tools and } \\
\text { personal genome [39-42] }\end{array}$ & $\begin{array}{l}\text { Development of new bio- } \\
\text { markers and genetic tests for } \\
\text { prognosis, therapy selection } \\
\text { and follow-up [43] }\end{array}$ \\
\hline
\end{tabular}

Table 1: Knowledge contributions of the human host and pathogen profiles to precision medicine.

will support PM. Reverse translational research can lead to advances in disease prognosis in order to distinguish genomic profiles and discovery of new biomarkers, which will direct the future of precision medicine.

\section{Acknowledgements}

Financial support from São Paulo Research Foundation (FAPESP) Grants 2008/53969-0, 2011/51626-1 and Coordination for the Improvement of Higher Education Personnel (CAPES) Grant 23038.001063/2012-01. L.C. Carrijo-Carvalho is a postdoctoral fellow of PNPD/CAPES. F.R.S. Carvalho is a fellow of the Young Researchers at Emerging Centers Program of FAPESP (Grant 2012/15603-0). D. Freitas is a Research Fellow of the National Council for Scientific and
Technological Development (CNPq, Grant 311612/2012-1). The authors thank the editor Joseph W. Eichenbaum and the anonymous reviewers for their helpful suggestions to the manuscript.

\section{References}

1. Pérez-Santonja JJ, Kilvington $S$, Hughes $R$, Tufail $A$, Matheson $M$, et al. (2003) Persistently culture positive acanthamoeba keratitis: in vivo resistance and in vitro sensitivity. Ophthalmology 110: 1593-1600.

2. Lee GA, Gray TB, Dart JK, Pavesio CE, Ficker LA, et al. (2002) Acanthamoeba sclerokeratitis: treatment with systemic immunosuppression. Ophthalmology 109: 1178-1182.

3. Sharma S, Garg P, Rao GN (2000) Patient characteristics, diagnosis, and treatment of non-contact lens related Acanthamoeba keratitis. $\mathrm{Br} J$ Ophthalmol 84: 1103-1108.

4. Dart JK, Saw VP, Kilvington S (2009) Acanthamoeba keratitis: diagnosis and treatment update 2009. Am J Ophthalmol 148: 487-499.

5. Claerhout I, Goegebuer A, Van Den Broecke C, Kestelyn P (2004) Delay in diagnosis and outcome of Acanthamoeba keratitis. Graefes Arch Clin Exp Ophthalmol 242: 648-653.

6. Narasimhan S, Madhavan HN, K LT (2002) Development and application of an in vitro susceptibility test for Acanthamoeba species isolated from keratitis to polyhexamethylene biguanide and chlorhexidine. Cornea 21: 203-205.

7. Arnalich-Montiel F, Lumbreras-Fernández B, Martín-Navarro CM, Valladares B, Lopez-Velez R, et al. (2014) Influence of acanthamoeba genotype on clinical course and outcomes for patients with acanthamoeba keratitis in Spain. J Clin Microbiol 52: 1213-1216.

8. Kashiwabuchi RT, Carvalho FR, Khan YA, de Freitas D, Foronda AS, et al. (2011) Assessing efficacy of combined riboflavin and UV-A light (365 nm) treatment of Acanthamoeba trophozoites. Invest Ophthalmol Vis Sci 52 : 9333-9338.

9. Martín-Navarro CM, Lorenzo-Morales J, López-Arencibia A, Reyes-Batlle M, Piñero JE, et al. (2014) Evaluation of Acanthamoeba myosin-IC as a potential therapeutic target. Antimicrob Agents Chemother 58: 2150-2155.

10. Hurt M, Neelam S, Niederkorn J, Alizadeh H (2003) Pathogenic Acanthamoeba spp secrete a mannose-induced cytolytic protein that correlates with the ability to cause disease. Infect Immun 71: 6243-6255.

11. Kim WT, Kong HH, Ha YR, Hong YC, Jeong HJ, et al. (2006) Comparison of specific activity and cytopathic effects of purified $33 \mathrm{kDa}$ serine proteinase from Acanthamoeba strains with different degree of virulence. Korean $\mathrm{J}$ Parasitol 44: 321-330.

12. de Souza Carvalho FR, Carrijo-Carvalho LC, Chudzinski-Tavassi AM, Foronda AS, de Freitas D (2011) Serine-like proteolytic enzymes correlated with differential pathogenicity in patients with acute Acanthamoeba keratitis. Clin Microbiol Infect 17: 603-609.

13. Schroeder JM, Booton GC, Hay J, Niszl IA, Seal DV, et al. (2001) Use of subgenic $18 \mathrm{~S}$ ribosomal DNA PCR and sequencing for genus and genotype identification of acanthamoebae from humans with keratitis and from sewage sludge. J Clin Microbiol 39: 1903-1911.

14. Booton GC, Joslin CE, Shoff M, Tu EY, Kelly DJ, et al. (2009) Genotypic identification of Acanthamoeba sp. isolates associated with an outbreak of acanthamoeba keratitis. Cornea 28: 673-676.

15. lovieno A, Oechsler RA, Ledee DR, Miller D, Alfonso EC (2010) Drug-resistant severe Acanthamoeba keratitis caused by rare T5 Acanthamoeba genotype. Eye Contact Lens 36: 183-184.

16. Goldschmidt P, Degorge S, Benallaoua D, Saint-Jean C, Batellier L, et al. (2009) New tool for the simultaneous detection of 10 different genotypes of Acanthamoeba available from the American Type Culture Collection. $\mathrm{Br} \mathrm{J}$ Ophthalmol 93: 1096-1100. 
Citation: Carvalho FRS, Carvalho LCC, Freitas DD (2014) Translational and Reverse Translational Research Supporting Precision Medicine: Acanthamoeba Keratitis as a Model of Linkage between Clinical and Basic Research Focused on Personalized Ophthalmology. J Ophthalmic Clin Res 1: 001.

17. Ikeda Y, Miyazaki D, Yakura K, Kawaguchi A, Ishikura R, et al. (2012) Assessment of real-time polymerase chain reaction detection of Acanthamoeba and prognosis determinants of Acanthamoeba keratitis. Ophthalmology 119: 1111-1119.

18. Qvarnstrom Y, Nerad TA, Visvesvara GS (2013) Characterization of a new pathogenic Acanthamoeba Species, A. byersi n. sp., isolated from a human with fatal amoebic encephalitis. J Eukaryot Microbiol 60: 626-633.

19. Corsaro D, Venditti D (2010) Phylogenetic evidence for a new genotype of Acanthamoeba (Amoebozoa, Acanthamoebida). Parasitol Res 107: 233-238.

20. Verani JR, Lorick SA, Yoder JS, Beach MJ, Braden CR, et al. (2009) National outbreak of Acanthamoeba keratitis associated with use of a contact lens solution, United States. Emerg Infect Dis 15: 1236-1242.

21. Khan N, Jarroll EL, Paget TA (2002) Molecular and physiological differentiation between pathogenic and nonpathogenic Acanthamoeba. Curr Microbiol 45: 197-202

22. Awwad ST, Heilman M, Hogan RN, Parmar DN, Petroll WM, et al. (2007) Severe reactive ischemic posterior segment inflammation in acanthamoeba keratitis: a new potentially blinding syndrome. Ophthalmology 114: 313-320.

23. Tu EY, Joslin CE, Sugar J, Shoff ME, Booton GC (2008) Prognostic factors affecting visual outcome in Acanthamoeba keratitis. Ophthalmology 115: 1998-2003.

24. Bouheraoua N, Gaujoux T, Goldschmidt P, Chaumeil C, Laroche L, et al. (2013) Prognostic factors associated with the need for surgical treatments in acanthamoeba keratitis. Cornea 32: 130-136.

25. Duguid IG, Dart JK, Morlet N, Allan BD, Matheson M, et al. (1997) Outcome of acanthamoeba keratitis treated with polyhexamethyl biguanide and propamidine. Ophthalmology 104: 1587-1592.

26. Hargrave SL, McCulley JP, Husseini Z (1999) Results of a trial of combined propamidine isethionate and neomycin therapy for Acanthamoeba keratitis. Brolene Study Group. Ophthalmology 106: 952-957.

27. Lim N, Goh D, Bunce C, Xing W, Fraenkel G, et al. (2008) Comparison of polyhexamethylene biguanide and chlorhexidine as monotherapy agents in the treatment of Acanthamoeba keratitis. Am J Ophthalmol 145: 130-135.

28. Alizadeh H, Apte S, El-Agha MS, Li L, Hurt M, et al. (2001) Tear IgA and serum IgG antibodies against Acanthamoeba in patients with Acanthamoeba keratitis. Cornea 20: 622-627.

29. Walochnik J, Obwaller A, Haller-Schober EM, Aspöck H (2001) Anti-Acanthamoeba IgG, IgM, and IgA immunoreactivities in correlation to strain pathogenicity. Parasitol Res 87: 651-656.

30. Alizadeh H, Tripathi T, Abdi M, Smith AD (2014) Pathogenic strains of Acanthamoeba are recognized by TLR4 and initiated inflammatory responses in the cornea. PLoS One 9: e92375.

31. Schröder NW, Schumann RR (2005) Single nucleotide polymorphisms of Toll-like receptors and susceptibility to infectious disease. Lancet Infect Dis 5: 156-164.

32. Iliff BW, Riazuddin SA, Gottsch JD (2012) A single-base substitution in the seed region of miR-184 causes EDICT syndrome. Invest Ophthalmol Vis Sci 53: 348-353.

33. von Holstein SL, Fehr A, Persson M, Nickelsen M, Therkildsen MH, et al (2014) Lacrimal gland pleomorphic adenoma and carcinoma ex pleomorphic adenoma: genomic profiles, gene fusions, and clinical characteristics. Ophthalmology 121: 1125-1133.

34. Li B, Sheng M, Xie L, Liu F, Yan G, et al. (2014) Tear proteomic analysis of patients with type 2 diabetes and dry eye syndrome by two-dimensional nano-liquid chromatography coupled with tandem mass spectrometry. Invest Ophthalmol Vis Sci 55: 177-186.

35. Chen Y, Huang K, Nakatsu MN, Xue Z, Deng SX, et al. (2013) Identification of novel molecular markers through transcriptomic analysis in human fetal and adult corneal endothelial cells. Hum Mol Genet 22: 1271-1279.
36. Roger JE, Hiriyanna A, Gotoh N, Hao H, Cheng DF, et al. (2014) OTX2 loss causes rod differentiation defect in CRX-associated congenital blindness. $J$ Clin Invest 124: 631-643.

37. Gordon WC, Bazan NG (2013) Mediator lipidomics in ophthalmology: targets for modulation in inflammation, neuroprotection and nerve regeneration. Curr Eye Res 38: 995-1005.

38. Agudo-Barriuso M, Lahoz A, Nadal-Nicolás FM, Sobrado-Calvo P, Piquer-Gil $\mathrm{M}$, et al. (2013) Metabolomic changes in the rat retina after optic nerve crush. Invest Ophthalmol Vis Sci 54: 4249-4259.

39. Kingsmore SF (2006) Multiplexed protein measurement: technologies and applications of protein and antibody arrays. Nat Rev Drug Discov 5: 310-320.

40. Mardis ER (2008) The impact of next-generation sequencing technology on genetics. Trends Genet 24: 133-141.

41. Koboldt DC, Steinberg KM, Larson DE, Wilson RK, Mardis ER (2013) The next-generation sequencing revolution and its impact on genomics. Cell 155 $27-38$

42. Dopazo J (2014) Genomics and transcriptomics in drug discovery. Drug Discov Today 19: 126-132.

43. Mirnezami R, Nicholson J, Darzi A (2012) Preparing for precision medicine. N Engl J Med 366: 489-491.

44. Carvalho FR, Foronda AS, Mannis MJ, Höfling-Lima AL, Belfort R Jr, et al. (2009) Twenty years of acanthamoeba keratitis. Cornea 28: 516-519.

45. Butler TK, Males JJ, Robinson LP, Wechsler AW, Sutton GL, et al. (2005) Six-year review of Acanthamoeba keratitis in New South Wales, Australia: 1997-2002. Clin Experiment Ophthalmol 33: 41-46.

46. Greenwell TH, Loh RS, Chehade M, Mills RA (2013) Misdiagnosis of orthokeratology-related Acanthamoeba keratitis as herpes simplex virus keratitis. Clin Experiment Ophthalmol 41: 418-420.

47. Lee JE, Oum BS, Choi HY, Yu HS, Lee JS (2007) Cysticidal effect on acanthamoeba and toxicity on human keratocytes by polyhexamethylene biguanide and chlorhexidine. Cornea 26: 736-741.

48. Alizadeh H, Silvany RE, Meyer DR, Dougherty JM, McCulley JP (1997) In vitro amoebicidal activity of propamidine and pentamidine isethionate against Acanthamoeba species and toxicity to corneal tissues. Cornea 16: 94-100.

49. Ehlers N, Hjortdal J (2004) Are cataract and iris atrophy toxic complications of medical treatment of acanthamoeba keratitis? Acta Ophthalmol Scand 82 228-231.

50. Tu EY, Joslin CE, Shoff ME (2010) Successful treatment of chronic stroma acanthamoeba keratitis with oral voriconazole monotherapy. Cornea 29 : 1066-1068

51. Bang S, Edell E, Eghrari AO, Gottsch JD (2010) Treatment with voriconazole in 3 eyes with resistant Acanthamoeba keratitis. Am J Ophthalmol 149: 66-69.

52. Johnson LB, Kauffman CA (2003) Voriconazole: a new triazole antifungal agent. Clin Infect Dis 36: 630-637.

53. Lorenzo-Morales J, Martín-Navarro CM, López-Arencibia A Arnalich-Montiel F, Piñero JE, et al. (2013) Acanthamoeba keratitis: an emerging disease gathering importance worldwide? Trends Parasitol 29: 181-187.

54. Meletiadis J, Chanock S, Walsh TJ (2006) Human pharmacogenomic variations and their implications for antifungal efficacy. Clin Microbiol Rev 19 763-787.

55. De Jonckheere JF (1980) Growth characteristics, cytopathic effect in cell culture, and virulence in mice of 36 type strains belonging to 19 different Acanthamoeba spp. Appl Environ Microbiol 39: 681-685.

56. Walochnik J, Obwaller A, Aspöck H (2000) Correlations between morphological, molecular biological, and physiological characteristics in clinical and nonclinical isolates of Acanthamoeba spp. Appl Environ Microbiol66: 4408-4413. 
Citation: Carvalho FRS, Carvalho LCC, Freitas DD (2014) Translational and Reverse Translational Research Supporting Precision Medicine: Acanthamoeba Keratitis as a Model of Linkage between Clinical and Basic Research Focused on Personalized Ophthalmology. J Ophthalmic Clin Res 1: 001.

- Page 6 of 6 •

57. Martín-Navarro CM, Lorenzo-Morales J, Machin RP, López-Arencibia A Garcia-Castellano JM, et al. (2013) Inhibition of 3-hydroxy-3-methylglutaryl-coenzyme A reductase and application of statins as a novel effective therapeutic approach against Acanthamoeba infections. Antimicrob Agents Chemother 57: 375-381.
58. Polat ZA, Obwaller A, Vural A, Walochnik J (2012) Efficacy of miltefosine for topical treatment of Acanthamoeba keratitis in Syrian hamsters. Parasitol Res 110: $515-520$. 